\title{
O Ensino de Espanhol em Escolas Pelotenses
}

\author{
The Teaching of Spanish in "Pelotense" Schools \\ La Enseñanza de Español en Escuelas "Pelotenses"
}

\author{
Erick Rosa Hernandes ${ }^{1}$ \\ 1erick.ufpel@gmail.com, Universidade Federal de Pelotas.
}

\begin{abstract}
Resumo
Este trabalho analisa a realidade do ensino de língua espanhola em escolas de Ensino Fundamental e Médio da cidade de Pelotas (RS). A ideia surgiu a partir de observações realizadas na disciplina de Estágio de Observação, do curso de Português e Espanhol da UFPel, no semestre 2015/1, a partir do momento em que se pôde perceber que o que o estagiário encontra em sala de aula não condiz com o que é estudado, principalmente em aulas de Linguística Aplicada. Para este estudo, utilizaram-se relatos obtidos pelo autor deste trabalho e de mais quatro informantes, os quais estagiaram em escolas da rede pública pelotense no mesmo período. A análise comparativa fundamentou-se principalmente em textos de teorias de aprendizagem de línguas estrangeiras e nos PCN's para o ensino de LE's no Brasil, de modo a contrastar o que afirmam os teóricos e o que realmente encontrou-se nas escolas. Este estudo ancora-se na abordagem qualitativa e na metodologia aplicada por serem formas de pesquisa mais relacionadas às experiências humanas, suas interpretações terem carácter mais flexível e por permitirem uma melhor aplicação ao ensino e aprendizagem de LE. Os resultados obtidos indicam que a realidade do ensino de espanhol nas escolas difere do que ensinam os professores na universidade, pois se percebeu que o ensino dessa língua é precário, não indo ao encontro do que sugerem os PCN's, no que se refere à transformação do aluno em agente discursivo em LE.
\end{abstract}

Palavras-chave: aprendizagem, espanhol, língua estrangeira.

\begin{abstract}
This paper analyzes the reality of Spanish language education in primary and secondary schools of the city of Pelotas (RS). The idea arose from observations in the discipline of observation practice, of Portuguese and Spanish course from UFPel, in 2015/1 semester, from the moment in which one might realize that what the trainee teacher is in the classroom does not match what is studied, especially in applied linguistics classes. For this study, using reports obtained by the author of this work and four more informants, which made their practice in public schools over the same period. The comparative analysis was based mainly on texts of theories of foreign language learning and the PCN's for teaching foreign language in Brazil, in order to contrast what claim the theorists and what they really met in schools. This study takes bases on a qualitative approach and methodology applied for being more related to human experiences, the interpretations have more flexible nature and by permitting a better application to the teaching and learning of foreign language. The results obtained indicate that the reality of teaching Spanish in schools differs from that teachers teach at the University, as it was realized that the real situation is precarious, not going how suggest the PCN's, with regard to the processing of the student in discursive agent in foreign language.
\end{abstract}

Keywords: learning, Spanish, foreign language.

\section{Resumen}

Este trabajo analiza la realidad de la enseñanza de lengua española en escuelas de primaria y secundaria de la ciudad de Pelotas (RS). La idea surgió a partir de observaciones realizadas en la disciplina de Práctica de Observación, del curso de Portugués y Español de la UFPel, en el semestre 2015/1, a partir del momento en que se pudo percibir que lo que el practicante encuentra en salón de clase no coincide con lo que es estudiado, 
principalmente en clases de Lingüística Aplicada. Para este estudio, se utilizó relatos obtenidos por el autor de este trabajo y de más cuatro informantes, los cuales observaron escuelas públicas en el mismo período. El análisis comparativo se basó principalmente en textos de teorías de aprendizaje de lenguas extranjeras y en los PCN's para la enseñanza de LE's en Brasil, para contrastar lo que afirman los teóricos y lo que fue encontrado en las escuelas. Este estudio utiliza el abordaje cualitativo y la metodología aplicada, pues son formas de investigación más relacionadas a las experiencias humanas, sus interpretaciones tienen carácter flexible y permiten mejor aplicación a la enseñanza y al aprendizaje de LE. Los resultados obtenidos indican que la realidad de la enseñanza de español en las escuelas difiere de lo que enseñan los profesores en la Universidad, pues se percibió que la enseñanza de esta lengua es precaria, no yendo al encuentro de lo que sugieren los PCN's en lo que se refiere a la transformación del alumno en agente discursivo en LE.

Palabras-clave: aprendizaje, español, lengua extranjera.

\section{Aporte teórico sobre aprendizagem de LE.}

Muito se pesquisa, há décadas, sobre o processo de aprendizagem de línguas estrangeiras, e ao longo do tempo surgiram várias teorias que tentam dar conta deste processo, o qual é extremamente complexo, tendo em vista a quantidade de fatores que nele interferem. Griffin (2011, p.33) afirma que tal processo, além de complexo, é difícil de medir. O linguista comenta acerca de três teorias, as quais ele considera principais neste campo de investigação. São elas: teorias nativistas, ambientalistas e interacionistas. O autor afirma que essa divisão "refleja las tres perspectivas principales desde las cuales se puede entender la investigación en este campo." (2011, p.33).

Segundo Griffin (2011, p.34), as teorias nativistas surgiram em oposição às ideias dos behavioristas, os quais defendiam que se aprendia língua na base de imitações e repetições. Desde a perspectiva dos nativistas, o ser humano já nasce com uma capacidade inata de aprender língua e, com isso, surge a conhecida Gramática Universal proposta por Chomsky. Ainda assim, os nativistas desconsideravam algumas questões que atualmente recebem muita atenção. Sobre isso, Griffin chama a atenção para o fato de que a perspectiva nativista é "más alejada del individuo como comunicador en sociedad." (2011, p. 34).

Outra teoria importante de ser comentada é a ambientalista. Sobre ela, o linguista anteriormente citado comenta que surgiu a partir de observações feitas em contextos de aprendizagem de línguas estrangeiras por motivos que obrigavam os aprendizes a saberem outra língua, como é o caso das línguas pidgin. Dessa forma, é possível afirmar que os ambientalistas "proponen como base las relaciones y los tipos de comunicación que surgen a partir de ellas." (GRIFFIN, 2011, p. 38). A terceira teoria, ou seja, a interacionista é a que vem sendo desenvolvida desde a década de 70 até a atualidade.

As teorias interacionistas preocupam-se, principalmente, com a função comunicativa das línguas e isso é o que faz dela, uma teoria mais adequada à proposta atual de ensino de 
línguas estrangeiras. Griffin (2011, p. 44) afirma que essa teoria serve de base às teorias do discurso e da variabilidade. Segundo o autor, a primeira tem como base a negociação do significado e a segunda, a pesar de ter a mesma base, tem como perspectiva um olhar mais sociocultural e mais voltado à aquisição de L2.

A partir dessa breve exposição das teorias mais importantes no que se refere ao aprendizado de línguas, é possível perceber que constantemente mudam as perspectivas, na tentativa de melhorar o processo de aprendizagem de LE, de modo que os alunos alcancem melhores níveis de competência comunicativa, algo que deve ser extremamente almejado pelos estudantes, mas também pelos professores. Entretanto, é importante destacar que não há uma teoria que dê conta de todo o processo de aprendizagem e, portanto, faz-se relevante o que afirma Baralo: "no podemos (...) pretender que una teoría, por muy multidimensional que sea, abarque todos los aspectos que hacen posible la apropiación de una nueva lengua." (BARALO, 2004, p.69).

Se as teorias sobre aprendizagem de LE são diversas, naturalmente, os métodos utilizados nas aulas também são variados e passaram por muitas reformulações ao longo do tempo. O mais antigo, conhecido como método tradicional, surge ainda no século XIX e tem como princípio alguns aspectos que foram encontrados nas aulas que foram observadas em 2015, ou seja, já no século XXI. Gargallo (1999, p. 59) destaca alguns princípios deste método, são eles: "memorización de reglas gramaticales, (...) memorización de listados de palabras, traducción directa e inversa y uso de la lengua materna del alumno (...)".

O método tradicional preocupava-se com a estrutura da língua, acreditando que ensinar uma língua estrangeira era apenas fazer com que o aluno memorizasse regras e que, assim, estaria aprendendo. Porém, com o avanço dos estudos sobre aprendizagem de LE, a língua foi sendo percebida cada vez mais como objeto utilizado para a comunicação e, portanto, o aprendiz necessita conseguir comunicar-se na língua por ele estudada. Sobre isso, Gargallo afirma:

Lo que hacemos en el aula ha de estar orientado a la consecución de un logro, y cuanto más efectivo sea el procedimiento, mayor será el logro. En definitiva, nuestro objetivo es que nuestros alumnos avancen en el uso efectivo de la lengua y para ello, pondremos en práctica cualquier mecanismo que consideremos eficaz. (GARGALLO, 1999, p. 48)

Com isso, surge como proposta metodológica a que conhecemos hoje como método comunicativo. O objetivo principal passa a ser o uso da língua em situações reais de comunicação, devendo o professor adotar outra postura no que se refere à metodologia de 
trabalho utilizada. Assim, decorar regras e vocabulário deve ser atividade complementar às atividades que deem ênfase na comunicação.

El enfoque comunicativo pone de relevancia el carácter funcional de la lengua como instrumento de comunicación, de manera que son las funciones lingüísticas el eje vertebrador del aprendizaje; asimismo, introduce el concepto de competencia comunicativa al ámbito de la enseñanza-aprendizaje de lenguas extranjeras, lo que supone una sensible ampliación de los objetivos del aprendizaje: el uso adecuado de la lengua exige conocimientos socioculturales, discursivos y estratégicos, además de los propiamente lingüísticos y funcionales. (GARGALLO, 1999, p. 68-69)

De acordo com o que foi exposto acima, é importante dizer que o aluno de LE precisa alcançar um bom nível de competência comunicativa, pois isso é o que garantirá o bom uso da língua feito pelo estudante. Para isso, é preciso realizar atividades em aula que proporcionem aos estudantes a oportunidade de utilizar a língua alvo e, em vista disso, é extremamente necessário que os alunos possam interagir entre si, de modo a simular um ambiente de imersão, como se o aprendiz já estivesse no ambiente onde a LE é utilizada. Sobre o tipo de atividade a ser realizada em aula, ou seja, atividade comunicativa, Gargallo defende:

Una actividad en la que el objetivo prioritario es la interacción comunicativa y, por lo tanto, aparecen implicadas dos o más destrezas lingüísticas; una actividad centrada en el contenido y en la que la forma constituye un aspecto secundario, una actividad que reproduce (...) una situación real (...). (GARGALLO, 1999, p. 69)

Algumas pessoas podem questionar sobre o motivo para utilizar a língua estrangeira em aula, pois em alguns casos os alunos não entenderão o que o professor diz. De qualquer modo, é importante considerar o que afirma Griffin sobre a geração de hipóteses que a pessoa faz ao entrar em contato com a LE. O linguista afirma que é a partir das hipóteses que o estudante progride em seu processo de aprendizagem e é através do contato com a língua objeto que o aluno poderá gerá-las. É necessário destacar que no caso das aulas de língua espanhola para alunos falantes do português brasileiro é possível utilizar a LE por se tratar de línguas relativamente semelhantes, pelo menos no que se refere ao léxico.

Para progresar en la adquisición de lenguas, el individuo percibe lengua (en principio incomprensible) de su entorno, lo asocia con sus conocimientos y genera hipótesis sobre los significados y usos. Después, ensaya estas hipótesis de manera activa (usando la lengua) o pasiva (observando cómo se usa la lengua) y según la retroalimentación (comprensión o incomprensión) producida por los ensayos, acepta o rechaza las hipótesis. (GRIFFIN, 2011, p. 91)

Outra questão que pode aparecer é sobre como fica a gramática na aula de língua estrangeira, já que hoje em dia o procedimento precisa ser diferente ao utilizado pelo método tradicional e ainda hoje utilizado por alguns professores. Sobre isso, os linguistas aqui estudados sustentam que não se pode descartá-la, pois as línguas são sistemas complexos e é 
necessário que em determinados momentos o professor apresente aos alunos regras que deverão ser obedecidas no momento de colocar em prática a LE estudada.

(...) la lengua es en primer lugar y por encima de todo, un instrumento de comunicación, pero también un complejo sistema de signos que se combinan por medio de reglas gramaticales, pragmáticas y culturales, y esta complejidad obliga a un conocimiento profundo de las mismas si queremos garantizar una competencia comunicativa en toda la extensión del concepto. (GARGALLO, 1999, p. 84)

Então, como trabalhar os conceitos lingüísticos da LE em aula? O professor pode utilizar-se de dois tipos de conhecimento: o implícito e o explícito. O implícito diz respeito ao tipo de conhecimento que o aluno adquire sem que o professor tenha que conceituá-lo formalmente. Já o explícito consiste na apresentação que faz o professor, de modo que os estudantes percebam mais diretamente a regra que é apresentada. Griffin explica que "los criterios de ordenar los conceptos lingüísticos en un contexto formal, obedecen más a la necesidad de secuenciar estos conceptos de modo que se puedan explicar bien." (GRIFFIN, 2011, p. 159).

O linguista apresenta o que defende Selinger (1979) sobre aprendizagem explícita: "aprendizaje explícito sirve para aprender reglas o normas que a su vez sirven para dirigir la atención del aprendiz a los puntos críticos de la lengua observada”. E continua: “(...) el aprendizaje implícito necesita del aprendizaje explícito para poder confirmar las asociaciones entre la información nueva y lo que sabe el aprendiz." (GRIFFIN, 2011, p. 161).

Porém, é importante que os professores de língua estrangeira percebam que não é adequado utilizar em suas aulas somente o tipo de instrução explícita, pois os conhecimentos adquiridos através deste tipo de instrução costumam ser guardados na memória de curto prazo do aprendiz, podendo, dessa forma, serem facilmente esquecidos. Griffin (2011, p. 161) comenta que Stevick (1980) sustenta que é necessário que a instrução explícita seja complementada pela implícita, para que os conhecimentos adquiridos em aula sejam armazenados na memória de longo prazo e, então, sejam lembradas com maior facilidade.

Dessa forma, fica claro que não podemos deixar de fazer com que nossos alunos pratiquem em aula, utilizando a língua estrangeira. Assim, terão a oportunidade de, em determinados momentos, eles mesmos descobrirem o funcionamento da língua e confirmarem suas hipóteses, além de poder relacionar os conhecimentos novos com os já obtidos. O aluno de LE precisa ter oportunidade para ser autônomo em seu processo de aprendizagem e nisso o professor de LE também tem sua parcela de responsabilidade. Sobre isso, Griffin comenta que "el aprendizaje de una segunda lengua se consigue en función de la variedad de situaciones 
en las que los aprendices tengan que manejar la lengua utilizando los conocimientos explícitos e implícitos." (GRIFFIN, 2011, p. 162).

Algo muito importante a ser comentado é o tipo de material que o professor pode utilizar em suas aulas. Existe uma gama de opções de materiais que podem ser aproveitados para que o aluno esteja em contato com a língua estudada. Não podemos esquecer que é muito importante que o estudante receba, constantemente, inputs autênticos para que possa perceber como a língua é utilizada pelos falantes nativos. Hoje em dia, além dos materiais tradicionais, existe a internet, a qual oferece ao professor um mundo inteiro para utilizar em suas aulas de língua estrangeira.

(...) los materiales destinados a la enseñanza del español como lengua extranjera se presentan en diversos soportes: a los clásicos - impreso, sonoro y visual - se suman en la actualidad los derivados de la informática - disquetes y CD-ROM -. Asimismo, la autopista de la información - internet - ofrece un importante caudal de recursos que pueden y deben ser aprovechados en el aula de español como lengua extranjera (...). (GARGALLO, 1999, p. 51)

A linguista afirma, ainda, que "la secuenciación de unidades didácticas constituye un todo coherente destinado al aprendizaje y (...) normalmente contienen los siguientes elementos: muestras de lengua, conceptualizaciones y actividades.” (GARGALLO, 1999, p.51-52). A autora defende que é necessário ter materiais didáticos variados, para que possa colocar em prática os procedimentos adequados em suas aulas, de modo a facilitar a aprendizagem.

É preciso pôr atenção em algo muito relevante e que pode causar problemas ao processo de aprendizagem de LE: a fossilização. Fossilização nada mais é do que a criação de raízes em dificuldades que os alunos possuem ao longo do processo, não podendo superá-las. Isso prejudica o bom uso da LE estudada, impedindo que o estudante possua um bom nível de competência linguística. Baralo sustenta que:

Con respecto a la prevención de las posibles fosilizaciones, el profesor podría proporcionar un contexto lingüístico rico y variado, de donde el estudiante pueda ir extrayendo datos que le permitan construir y constatar sus hipótesis. En este sentido, parece conveniente evitar las explicaciones simplistas o excesivamente complicadas o teóricas, que pueden complicar o entorpecer el proceso natural de adquisición. (BARALO, 2004, p. 69-70)

Além de tudo o que já foi exposto sobre aprendizagem de LE, é indispensável comentar o que afirmam os PCN's para o ensino de língua estrangeira no Brasil. Este documento defende que o aluno precisa ser transformado em agente discursivo, o que vai ao encontro do que afirmam os linguistas acima citados. Com isso, é reforçada, uma vez mais, a necessidade de fazer com que os aprendizes sejam capazes de criar e perceber significados utilizando a LE. 
A aprendizagem de uma língua estrangeira deve garantir ao aluno seu engajamento discursivo, ou seja, a capacidade de se envolver e envolver outros no discurso. Isso pode ser viabilizado em sala de aula por meio de atividades pedagógicas centradas na constituição do aluno como ser discursivo, ou seja, sua construção como sujeito via Língua Estrangeira. Essa construção passa pelo envolvimento do aluno com os processos sociais de criar significados por intermédio da utilização de uma língua estrangeira. (BRASIL, 1998, p. 19)

\section{A realidade encontrada nas escolas.}

Nesta seção, serão comentadas as informações recebidas para este artigo. Tais informações foram cedidas por cinco estagiários do semestre 2015-1, da disciplina de Estágio de Observação de Língua Espanhola. Para isso, cada um respondeu a um questionário de cinco perguntas, as quais permitiam que as respostas fossem desenvolvidas de acordo com a necessidade que o informante tinha de expor o que pôde observar nas aulas de espanhol. Todos os dados utilizados para este artigo foram colhidos em escolas da rede pública da cidade de Pelotas (RS). A seguir, são apresentadas as perguntas que os informantes responderam:

1. Como foi o trabalho do professor de Espanhol durante o período de observação?

2. Falou-se em Espanhol nas aulas?

3. O professor demonstrava-se motivado?

4. Os alunos demonstravam-se motivados?

5. Como você enxerga o ensino de Espanhol na escola que você observou?

A partir das respostas obtidas, tem-se o objetivo de poder olhar com mais atenção para a realidade do ensino de língua espanhola em escolas pelotenses, de modo a contribuir para a melhoria da qualidade do ensino dessa língua estrangeira, para que as aulas dessa disciplina não sejam vistas como apenas horário para completar o currículo e sem muita importância. Afinal, atualmente é extremamente importante conhecer e saber utilizar outros idiomas devido à globalização e às exigências do mercado de trabalho. Para a apresentação dos dados, convencionou-se identificar os informantes apenas como "informantes" para que ninguém se sinta exposto e até mesmo ofendido.

Quando questionados sobre como foi o trabalho do professor de língua espanhola em sala de aula, todos os informantes deram respostas que vão a uma mesma direção, mesmo que com informações diferentes. É possível perceber que a maneira como os professores atuaram em aula não estão de acordo com o que as teorias anteriormente comentadas propõe, 
principalmente no que diz respeito à metodologia e tipos de atividades que devem ser realizadas. Podem-se listar as respostas à primeira pergunta com os seguintes tópicos:

1. Aulas não preparadas previamente.

2. Professor não lembrava o que deveria ensinar em determinadas aulas.

3. Exposição de regras gramaticais e listas de vocabulário.

4. Professor quase não trabalhou, permitindo que os alunos conversassem sobre assuntos alheios às aulas.

5. Professor não explicava as atividades, preferindo dar as respostas no final da aula.

6. Ensino de conteúdos básicos, porém que não foram aprendidos pelos alunos.

7. Aula resumia-se apenas a passar exercícios no quadro.

Essas informações são alarmantes, pois dificilmente alguém aprenderá outro idioma sendo exposto a esse tipo de aula de LE. Percebe-se que a maneira como os professores têm trabalhado assemelha-se mais ao tipo de metodologia utilizada no século XIX, quando era vigente o método tradicional. Porém, é preciso refletir e perceber que, se hoje a perspectiva sobre aprendizagem de línguas mudou, é porque as mais antigas possuíam carências, as quais devem ser superadas por propostas metodológicas inovadoras e que façam dos estudantes, seres capazes de utilizar outro idioma.

Já foi exposto que é importante que se utilize a língua estrangeira em aula, para que o aprendiz tenha momentos de contato com a língua estrangeira. Dessa forma, esperava-se encontrar nas escolas professores que falassem em espanhol com seus alunos, dando-lhes a oportunidade de estar em contato pelo menos com o espanhol falado pelo professor. Porém, não foi isso o que se pôde encontrar nas escolas. Todos os professores observados falavam em português com seus alunos, sendo utilizado o espanhol somente em momentos específicos, como para dizer "buenas tardes" ao chegar em aula e ler o enunciado dos exercícios do livro didático.

A Linguística Aplicada explica como o aluno avança no processo de aprendizagem de uma LE. Os professores parecem desconhecer as informações sobre a geração de hipóteses que o estudante faz para compreender como a língua funciona, já que não lhes permitem sequer escutar alguma fala em língua espanhola. Dessa forma, não há como criar qualquer tipo de hipótese, pois memorizar palavras descontextualizadas e conjugação verbal não faz com que o aluno pense em como a língua se organiza e quais os significados emitidos na produção de discursos. 
Com isso, é preciso tentar entender o motivo que leva os professores a atuarem dessa maneira. A palavra que explica o que acontece é desmotivação. Todos os informantes afirmam que os professores observados dizem não estar motivados para realizar seu trabalho e explicam que a atual situação da educação no país é a principal responsável por isso. Baixa valorização que recebe o profissional da educação, tanto por parte do governo, quanto por parte dos próprios alunos e o pequeno espaço que recebem as línguas estrangeiras nas escolas fazem com que os professores não encontrem ânimo, e até mesmo possibilidades em alguns momentos, para desenvolver um trabalho adequado ao que propõe a LA.

Essa desmotivação por parte dos professores contribui para gerar um problema muito preocupante, que é a desmotivação dos próprios alunos. Os estudantes das turmas observadas também se mostram desmotivados, alguns sequer enxergando motivos para aprender espanhol. Sabemos que os professores não são os únicos responsáveis por fazer com que os alunos tenham interesse pelas aulas, porém, é a partir de aulas interessantes e atrativas que os alunos poderão despertar a vontade de aprender outra língua. Precisamos mostrar aos estudantes que saber comunicar-se em outro idioma é fundamental e que o processo de aprendizagem pode ser divertido e prazeroso.

Ao final do questionário, quando perguntados sobre como enxergam o ensino de língua espanhola na escola que cada informante observou, as respostas não foram diferentes do que era esperado, devido às respostas fornecidas às questões anteriores. Todos veem o ensino de espanhol como algo precário, deficiente e, até mesmo, sem sentido. Todos perceberam que os alunos saem da escola sem ser capazes de comunicar-se utilizando a língua espanhola, sem sequer ter aprendido algo nos poucos minutos que a escola destina para a aula de língua estrangeira. Essa realidade não vai ao encontro do que sugerem os PCN's, no que se refere à formação do aluno em agente discursivo em LE.

\section{Considerações finais.}

Ao final desta pesquisa, foi possível notar que existe uma distância muito grande entre as propostas das teorias de aprendizagem de língua estrangeira e a prática realizada em sala de aula. Todos os anos, os alunos passam pelas aulas de língua espanhola, chegando ao final sem ser capazes de estabelecer qualquer tipo de comunicação na língua. Isso configura uma enorme perda de tempo, pois não vale a pena ficar, mesmo que por apenas cinquenta minutos, em uma aula na qual não se aprende nada. Os alunos seguem sem compreender e sem saber usar a língua espanhola. 
Em momento algum se teve o objetivo de ofender ou afrontar os professores das escolas públicas pelotenses, mas sim provocá-los, de modo a fazer com que reflitam e repensem suas práticas em sala de aula para que, assim, os alunos possam levar para suas vidas o que devem aprender na escola. Precisamos despertar nos estudantes o interesse pelo estudo de outro idioma, e isso acontecerá a partir do momento em que eles percebam a importância de aprendê-lo.

Além disso, este artigo não se destina somente aos professores de espanhol, mas também aos responsáveis pela organização do currículo escolar, os quais reservam uma carga horária muito baixa para as línguas estrangeiras, o que torna quase inviável o ensino das mesmas. Por fim, tenta-se, também, chamar a atenção do governo brasileiro sobre a baixa valorização que é dada aos professores, pois isso reduz o nível de motivação para estar em sala de aula, pois é de conhecimento de todos os problemas que um professor deve enfrentar ao entrar na escola. Apenas a partir do momento em que a educação for vista como prioridade pelo país, o ensino de língua espanhola, e de qualquer outra disciplina, melhorará significativamente.

\section{Referências}

BARALO, Marta. La adquisición del español como lengua extranjera. 2 ed. Madrid: Arco Libros, 2004.

Brasil. Secretaria de Educação Fundamental. Parâmetros curriculares nacionais: terceiro e quarto ciclos do ensino fundamental: língua estrangeira Secretaria de Educação Fundamental. Brasília: MEC/SEF, 1998.

GARGALLO, Isabel Santos. Lingüística aplicada a la enseñanza-aprendizaje del español como lengua extranjera. Madrid: Arco Libros, 1999.

GRIFFIN, Kim. Lingüística aplicada a la enseñanza del español como 2/L. 2 ed. Madrid: Arco Libros, 2011. 